Arq. Bras. Med. Vet. Zootec., v.67, n.2, p.365-371, 2015

\title{
Reação de fase aguda e sua relação com o desempenho de cavalos em competição de longa distância
}

\author{
[Acute phase reaction and its relationship with performance \\ horses competing long distance] \\ L.A. Amaral ${ }^{1}$, C.F. Paz $^{2}$, C. Haetinger ${ }^{1}$, E.P. Crespo $^{3}$, C.E.W. Nogueira ${ }^{4}$ \\ ${ }^{1}$ Aluna de pós-graduação - Universidade Federal de Pelotas - UFPel - Pelotas, RS \\ ${ }^{2}$ Aluno de pós-graduação - Escola de Veterinária - UFMG - Belo Horizonte, MG \\ ${ }^{3}$ Aluno de graduação - Universidade Federal de Pelotas - UFPel - Pelotas, RS \\ ${ }^{4}$ Faculdade de Medicina Veterinária - Universidade Federal de Pelotas - UFPel - Pelotas, RS
}

\begin{abstract}
RESUMO
O exercício físico é um dos estímulos fisiológicos mais estressantes que um animal pode sofrer e, dependendo de sua intensidade, sugere-se que possa gerar uma reação mediada por proteínas de fase aguda (PFA). O objetivo deste estudo foi caracterizar a reação de fase aguda e sua relação com o desempenho de cavalos submetidos a uma competição de longa distância. $O$ experimento foi desenvolvido durante a Marcha de Resistência anual promovida pela Associação Brasileira de Criadores de Cavalos Crioulos (ABCCC), composta por um percurso de $750 \mathrm{~km}$ percorrido durante 15 dias. Foram avaliados 23 equinos, os quais foram divididos em dois grupos, sendo o grupo 1 composto pelos 10 primeiros colocados na competição e o grupo 2 formado pelos 13 animais que concluíram a competição em colocações inferiores ou foram desclassificados antes de terminar a prova. Efetuaram-se coletas sanguíneas em repouso (dia 0) e no último dia de competição, e foi realizado o teste de eletroforese em gel de poliacrilamida contendo dodecil sulfato de sódio (SDS-PAGE) para identificar as proteínas (albumina, haptoglobina, ceruloplasmina, transferrina, imunoglobulina G, imunoglobulina A, glicoproteína ácida e proteína de peso molecular de $23 \mathrm{kDa}$ ). Os resultados demonstraram que o exercício físico imposto influenciou de forma significativa $(\mathrm{P}<0,0001)$ as concentrações séricas de haptoglobina, ceruloplasmina, imunoglobulina A, glicoproteína ácida e proteína de peso molecular de 23kDa. Quando comparados os resultados dos grupos estudados, observou-se que a concentração de haptoglobina após a competição foi superior no grupo de animais com baixo desempenho (grupo 2). Conclui-se que a competição de longa duração é capaz de gerar reação de fase aguda e que o monitoramento da concentração de haptoglobina pode ser um sinalizador de processo inflamatório e baixo desempenho.
\end{abstract}

Palavras-chave: reação de fase aguda, exercício, equinos, proteínas

\begin{abstract}
Exercise is one of the most stressful physiologic stimuli that an animal might suffer, depending on its intensity it may generate a reaction mediated by acute phase proteins (APP). The aim of this study was to characterize the acute phase reaction and its relation to performance horses subjected to long distance competition. The experiment was conducted during the annual March of Resistance promoted by the Brazilian Association of Crioulo Horse Breeders (ABCCC), composed of a $750 \mathrm{~km}$ route traveled during 15 days. 23 horses which were divided in two groups, one group composed by the 10 best placed horses and the second group consisting of 13 animals that have completed the competition in other positions or were disqualified before concluding the race were evaluated. All horses at the beginning of the competition (day 0) and on the last day of competition were subjected to collection of blood and SDSpolyacrylamide gel (SDS-PAGE) electrophoresis was used to measure APPs concentrations (albumin, ceruloplasmin, transferrin, haptoglobin, acid glycoprotein, immunoglobulin $G$, immunoglobulin $A$ and a
\end{abstract}

Recebido em 30 de setembro de 2013

Aceito em 21 de agosto de 2014

E-mail: lo1amaral@gmail.com 
protein with molecular weight of $23 \mathrm{kDa}$ ). By the evaluation of the results, it was observed that exercise had a highly significant influence $(P<0.0001)$ in the serum concentrations of the ceruloplasmin, haptoglobin, acid glycoprotein, immunoglobulin A and protein with molecular weight of $23 \mathrm{kDa}$. When comparing the results of the study groups it was observed that the concentration of haptoglobin after the competition was higher in the group of animals with low performance (group 2). We conclude that the long term competition is able to generate acute phase reaction and monitoring the concentration of haptoglobin may be an indicator of inflammation and low performance.

Keywords: acute phase reaction, exercise, horses, proteins

\section{INTRODUÇÃO}

O exercício físico é um dos estímulos fisiológicos mais estressantes que um animal pode sofrer; durante esse período, inúmeras reações metabólicas são mediadas na tentativa de adaptação do organismo (Gondin et al., 2013). Sugere-se que a reação de fase aguda mediada por proteínas pró e anti-inflamatórias, ou também chamadas de proteínas de fase aguda (PFA), tenha importante papel no processo de adaptação muscular. Essas proteínas são responsáveis por promover a sinalização imunológica e reparação de tecidos lesados durante o esforço físico (Ceciliane et al., 2002).

As proteínas de fase aguda podem ser classificadas em positivas, representadas pela glicoproteína ácida, haptoglobina, ceruloplasmina, macroglobulina e amiloide $\mathrm{A}$, e em negativas, como a albumina e a transferrina, cujas concentrações séricas tendem a decrescer em condições inflamatórias (Murata et al., 2004; Cerón et al., 2005). De maneira geral, as PFA possuem a finalidade de inibir a continuidade do dano tecidual, isolando e destruindo o organismo agressor e ativando o processo de reparação necessária para o retorno do organismo às funções normais (Cerón et al., 2005).

Apesar de inúmeras controvérsias, a resposta de fase aguda é relatada após o exercício prolongado em seres humanos. Essa reação induzida pelo exercício foi caracterizada por alterações nas concentrações séricas de citocinas pró-inflamatórias, proteína C-reativa e haptoglobina. Tem sido proposto que esse quadro resulta da depleção de glicogênio e danos no músculo esquelético (Fallon, 2001).

Em equinos, as alterações nas concentrações de haptoglobina têm sido relatadas em cavalos de corrida durante e após serem exercitados em esteira (Masini et al., 2003), podendo ser o resultado de hemólise intravascular induzida pelo exercício. Cywinska et al. (2010) determinaram que elevadas concentrações séricas de Amiloide A sérica podem ser um indicador não específico de falta de condicionamento físico de cavalos de enduro, resultando na eliminação durante a competição de longa distância. Contudo, Gondin et al. (2013), apesar de terem observado aumento nas concentrações séricas de proteínas de fase aguda em cavalos de polo, consideraram um processo de resposta fisiológica dos competidores.

Se comprovada sua ocorrência, a mensuração da concentração sérica de proteínas de fase aguda pode ser utilizada como ferramenta na avaliação de processos inflamatórios agudos antes e após o exercício e ainda serem utilizados no intuito de entender sua relação com o desempenho dos animais durante a atividade física prolongada.

O objetivo deste estudo foi caracterizar a reação de fase aguda e sua relação com o desempenho de cavalos submetidos a uma competição de longa distância.

\section{MATERIAIS E MÉTODOS}

O estudo foi conduzido durante a Marcha anual de Resistência promovida pela Associação Brasileira de Criadores de Cavalos Crioulos (ABCCC), na cidade de Santo Antônio da Patrulha, Rio Grande do Sul, durante o mês de julho de 2012. As etapas ocorreram em uma propriedade rural localizada no interior do município.

Foram avaliados 23 animais participantes, sendo 13 fêmeas e 10 machos, com peso médio de $430 \pm 35 \mathrm{~kg}$.

O regulamento da competição determina que todos os animais inscritos sejam entregues à comissão organizadora para serem soltos em um 
ambiente coletivo durante 30 dias prévios ao início da prova. Esse ambiente era composto exclusivamente de pastagem de azevém (Lolium multiflorum Lam) e cochos com água ad libidum. Essa mesma área era utilizada para os animais descansarem e alimentarem-se durante os 15 dias de competição. Consta também no regulamento a proibição da utilização de medicamentos, suplementos e alimento concentrado durante esses 45 dias.

Após o termino da competição, os animais foram divididos em dois grupos conforme seus desempenhos. O grupo 1 foi composto pelos 10 primeiros colocados e o grupo 2 foi formado pelos outros 13 animais, que ficaram em colocações inferiores ou foram desclassificados antes de concluir a prova.

Com relação às coletas de material, todos os animais, previamente ao início da competição (dia 0) e após o último dia (dia 15) desta, foram submetidos à coleta de amostras sanguíneas em tubos sem anticoagulante.

As amostras foram centrifugados por $5 \mathrm{~min}$ a 400G e separado o soro para congelamento a $80 \mathrm{C}$ e posterior análise laboratorial.

A concentração plasmática de proteína total foi determinada pelo método colorimétrico, por reação com o biureto, utilizando-se kit comercial (Labtest), e a leitura, realizada por espectofotômetro. Para obtenção da concentração das frações proteicas, utilizou-se eletroforese em gel de acrilaminada contendo dodecil sulfato de sódio (SDS-PAGE), conforme técnica descrita por Laemmli (1970). Após o fracionamento, o gel foi corado durante $10 \mathrm{~min}$ em solução de azul de coomassie e, em seguida, colocado em solução de ácido acético a $7 \%$ para retirar o excesso de corante, até que as frações proteicas se apresentassem nítidas. As concentrações dessas proteínas foram determinadas em densitômetro computadorizado (Shimadzu CS 9301 - Tóquio, Japão.). Como referência, utilizou-se uma solução marcadora (Sigma Saint Louis, EUA) com pesos moleculares $29.000,45.000,66.000,97.400,116.000 \mathrm{e}$ 205.000 dáltons (Da), além de proteínas purificadas2 - albumina, IgG, haptoglobina e transferrina.
O delineamento experimental utilizado foi inteiramente ao acaso, em parcelas subdivididas, sendo os grupos 1 e 2 as parcelas e os momentos, as subparcelas.

As análises estatísticas foram realizadas através do programa Statistical Analysis System (SAS Institute Inc. Cary, NC, EUA). Para verificar a distribuição das variáveis, os dados foram testados quanto à normalidade pelos testes de Shapiko Wilk e Lilliefors considerando significância de 5\%. Foi efetuada a análise de variância simples com comparação entre médias através do teste de LSD, sendo considerado significante $\mathrm{P}<0,05$.

Este estudo foi aprovado pelo Comitê de Ética e Experimentação Animal $n^{\circ} 4602 / 2010$ na Universidade Federal de Pelotas.

\section{RESULTADOS}

Foram avaliados 23 animais durante a competição, sendo que 17 completaram os percursos durante 15 dias e seis foram desclassificados durante esse período.

Na Tabela 1 estão apresentados os valores médios e erros padrão para as concentrações séricas de haptoglobina, glicoproteína ácida, ceruloplasmina, imunoglobulina A, imunoglobulina $\mathrm{G}$, albumina, proteína plasmática total, transferrina e uma proteína não identificada com peso molecular de $23 \mathrm{kDa}$ para os grupos $1 \mathrm{e}$ 2 nos momentos antes e após a competição.

$\mathrm{Na}$ Tabela 2 estão apresentados os valores médios, erros padrão e diferenças porcentuais nas concentrações proteicas de haptoglobina, glicoproteína ácida, ceruloplasmina, imunoglobulina A, imunoglobulina $\mathrm{G}$, albumina, proteína plasmática total, transferrina e uma proteína não identificada com peso molecular de $23 \mathrm{kDa}$.

$\mathrm{Na}$ avaliação dos resultados obtidos na Tabela 2, foi possível observar que o exercício físico imposto influenciou de forma significativa $(\mathrm{P}<0,0001)$ as concentrações séricas das proteínas avaliadas, exceto a transferrina, imunoglobulina $\mathrm{G}$ e albumina. 
Tabela 1. Valores médios ( \pm erro padrão da média) das proteínas inflamatórias do grupo 1 e 2 avaliadas no momento antes (D0) e após a competição (D15)

\begin{tabular}{|c|c|c|c|}
\hline Proteína $(m g / d l)$ & Grupo & $\mathrm{XD} 0 \pm \mathrm{SD} 0$ & XD15 \pm SE D15 \\
\hline \multirow{2}{*}{ Haptoglobina } & G1 & $46,2 \pm 4,5 \mathrm{a}, \mathrm{A}$ & $70,1 \pm 6,9 \mathrm{a}, \mathrm{B}$ \\
\hline & $\mathrm{G} 2$ & $53,8 \pm 2,4 \mathrm{a}, \mathrm{A}$ & $92,7 \pm 7,6 b, B$ \\
\hline \multirow{2}{*}{ Glicoproteína ac. } & G1 & $4,3 \pm 1,1 \mathrm{a}, \mathrm{A}$ & $13,1 \pm 2,8 \mathrm{a}, \mathrm{B}$ \\
\hline & $\mathrm{G} 2$ & $5,6 \pm 0,8 \mathrm{a}, \mathrm{A}$ & $16 \pm 2,6 a, B$ \\
\hline \multirow{2}{*}{ Ceruloplasmina } & G1 & $2,4 \pm 0,5 \mathrm{a}, \mathrm{A}$ & $4,3 \pm 0,4 \mathrm{a}, \mathrm{B}$ \\
\hline & $\mathrm{G} 2$ & $3,1 \pm 0,7 \mathrm{a}, \mathrm{A}$ & $5,2 \pm 0,7 \mathrm{a}, \mathrm{B}$ \\
\hline \multirow{2}{*}{$\operatorname{IgA}$} & G1 & $150,9 \pm 5,4 a, A$ & $85,3 \pm 11,3 \mathrm{a}, \mathrm{B}$ \\
\hline & $\mathrm{G} 2$ & $156,8 \pm 11,2 \mathrm{a}, \mathrm{A}$ & $107 \pm 17,3 a, B$ \\
\hline \multirow{2}{*}{$\operatorname{IgG}$} & G1 & $1.376 \pm 67,7 \mathrm{a}, \mathrm{A}$ & $1.431 \pm 65,1 \mathrm{a}, \mathrm{B}$ \\
\hline & $\mathrm{G} 2$ & $1.390,2 \pm 52,3 \mathrm{a}, \mathrm{A}$ & $1.500 \pm 76,8 \mathrm{a}, \mathrm{B}$ \\
\hline \multirow{2}{*}{ Albumina } & G1 & $4.186 \pm 110 \mathrm{a}, \mathrm{A}$ & $4.126 \pm 65,1 \mathrm{a}, \mathrm{B}$ \\
\hline & $\mathrm{G} 2$ & $4.082 \pm 130 \mathrm{a}, \mathrm{A}$ & $3.916,5 \pm 307 \mathrm{a}, \mathrm{B}$ \\
\hline \multirow{2}{*}{ PPT } & G1 & $7.200 \pm 200 \mathrm{a}, \mathrm{A}$ & $7.600 \pm 200 a, B$ \\
\hline & $\mathrm{G} 2$ & $7.500 \pm 100 \mathrm{a}, \mathrm{A}$ & $7.800 \pm 100 \mathrm{a}, \mathrm{B}$ \\
\hline \multirow{2}{*}{ Transferrina } & G1 & $435,6 \pm 17,6 a, A$ & $419,2 \pm 14,8 \mathrm{a}, \mathrm{B}$ \\
\hline & $\mathrm{G} 2$ & $421,7 \pm 11,5 \mathrm{a}, \mathrm{A}$ & $449,4 \pm 17,7 \mathrm{a}, \mathrm{B}$ \\
\hline \multirow{2}{*}{ Proteína $23 \mathrm{kDa}$} & G1 & $436,2 \pm 17,9 \mathrm{a}, \mathrm{A}$ & $529,1 \pm 27,1 \mathrm{a}, \mathrm{B}$ \\
\hline & $\mathrm{G} 2$ & $419 \pm 13 \mathrm{a}, \mathrm{A}$ & $508,5 \pm 19,1 \mathrm{a}, \mathrm{B}$ \\
\hline
\end{tabular}

Letras maiúsculas distintas indicam diferença significativa entre os momentos pelo Teste LSD (P<0,05). Letras minúsculas distintas indicam diferença significativa entre os grupos pelo Teste LSD $(\mathrm{P}<0,05)$. Valores de referência segundo Jacobsen (2007) para haptoglobina: 20-100mg/dl; glicoproteína ác.: 7-9mg/dl; ceruloplasmina: 30-40mg/dl; IgA: $60-350 \mathrm{mg} / \mathrm{dl}$; IgG: $500-2.000 \mathrm{mg} / \mathrm{dl}$; albumina: 3.000-4.000mg/dl; PPT (proteína plasmática total): $7.000-$ $8.000 \mathrm{mg} / \mathrm{dl}$; transferrina: $230-550 \mathrm{mg} / \mathrm{dl}$; proteína de $23 \mathrm{kDa}$ : não foram estabelecidos valores de referência para espécie.

Tabela 2. Valores médios ( \pm erro padrão da média) e diferenças porcentuais nas concentrações proteicas entre os momentos antes (D0) e após a competição (D15)

\begin{tabular}{lccc}
\hline Proteínas $(\mathrm{mg} / \mathrm{dl})$ & $\mathrm{XD} 0 \pm \mathrm{SD0}$ & $\mathrm{XD} 15 \pm \mathrm{SE} \mathrm{D} 15$ & Percentagem \\
\hline Haptoglobina & $50,5 \pm 5 \mathrm{a}$ & $82,9 \pm 5,6 \mathrm{~b}$ & $64,2 \%$ \\
Glicoproteína ác. & $5,1 \pm 0,6 \mathrm{a}$ & $14,7 \pm 1,9 \mathrm{~b}$ & $188,2 \%$ \\
Ceruloplasmina & $2,7 \pm 0,4 \mathrm{a}$ & $4,8 \pm 0,5 \mathrm{~b}$ & $77,8 \%$ \\
$\mathrm{IgA}$ & $153,9 \pm 6,6 \mathrm{a}$ & $89,7 \pm 8,6 \mathrm{~b}$ & $-41,7 \%$ \\
$\mathrm{IgG}$ & $1.384,3 \pm 42,2 \mathrm{a}$ & $1.470,2 \pm 51,2 \mathrm{a}$ & $6,2 \%$ \\
Albumina & $4.132,3 \pm 86,8 \mathrm{a}$ & $4.008 \pm 180,5 \mathrm{a}$ & $-3 \%$ \\
PPT & $7.400 \pm 100 \mathrm{a}$ & $7.700 \pm 100 \mathrm{~b}$ & $4,1 \%$ \\
Transferrina & $427,3 \pm 10,2 \mathrm{a}$ & $436,3 \pm 12,1 \mathrm{a}$ & $2,1 \%$ \\
Proteína 23kDa & $426,6 \pm 10,9 \mathrm{a}$ & $517,5 \pm 15,7 \mathrm{~b}$ & $21,3 \%$ \\
\hline
\end{tabular}

A significância entre os valores das colunas estão indicadas por letras minúsculas. Valores de referência segundo Jacobsen (2007) para haptoglobina: 20-100mg/dl; glicoproteína ác.: 7-9mg/dl; ceruloplasmina: 30-40mg/dl; IgA: 60350mg/dl; IgG: 500-2.000mg/dl; albumina: 3.000-4.000mg/dl; PPT (proteína plasmática total): 7.000-8.000mg/dl; transferrina: $230-550 \mathrm{mg} / \mathrm{dl}$; proteína de 23kDa: não foram estabelecidos valores de referência para espécie.

\section{DISCUSSÃO}

A marcha de resistência da raça Crioula foi caracterizada por Amaral et al. (2013) como uma prova de elevada exigência física associada a intensa lesão muscular e catabolismo proteico.

Os resultados demonstraram que o exercício físico imposto influenciou de forma significativa nas concentrações séricas de haptoglobina, ceruloplasmina, imunoglobulina A, glicoproteína ácida e proteína de peso molecular de $23 \mathrm{kDa}$ quando avaliadas as médias gerais dos participantes.

Foi observado um aumento significativo de $62,2 \%$ na concentração sérica de haptoglobina sérica entre o início e o final da competição. Essa 
proteína é produzida principalmente pelos hepatócitos, e seu papel é impedir a perda de ferro pela formação de complexos estáveis com a hemoglobina livre no sangue (Murata et al., 2004). Sua elevação pode estar relacionada a qualquer processo inflamatório, e seu aumento em equinos foi observado após procedimentos cirúrgicos (Kent, 1992), artrite não infecciosa (Hulten et al., 2002) e laminite induzida por carboidratos (Fagliari et al., 1997). Sua diminuição está relacionada a quadros de hemólise induzida pelo exercício, conforme descrito por Masini et al. (2003). Gondin et al. (2013), avaliando cavalos em uma competição de polo, observaram uma sutil elevação dos valores de haptoglobina, porém não caracterizaram o quadro como reação de fase aguda. Quando comparadas as concentrações séricas de haptoglobina dos dois grupos de cavalos avaliados, foi observado que, ao final da competição, o grupo 2, composto por animais com baixo desempenho, apresentaram valores dessa proteína mais elevados que nas concentrações séricas observadas no grupo 1 . Esse dado pode corroborar a hipótese de que a reação de fase aguda que ocorre durante o exercício prolongado influencia de forma negativa o desempenho final dos animais em competição. Pode ainda sinalizar a intensidade do processo inflamatório gerado, assim como ocorre com outros insultos ao organismo.

Da mesma forma como a haptoglobina, as concentrações séricas gerais de glicoproteína ácida e ceruloplasmina elevaram-se $188,2 \%$ e $77,8 \%$, respectivamente. A glicoproteína ácida tem sua elevação associada a processos inflamatórios de caráter crônico, principalmente envolvendo dano endotelial (Fournier et al., 2000). Em equinos, sua dosagem ainda tem pouca descrição, porém, no presente estudo, essa proteína obteve a elevação mais expressiva quando comparada às demais proteínas avaliadas. A ceruloplasmina tem importante papel no metabolismo e transporte do cobre, e tem sua elevação relacionada ao aumento de radicais livres do oxigênio produzidos durante a inflamação (Gruys et al., 1994; Hirvonen, 2000). Gondin et al. (2013) descreveram seu aumento após um jogo-treino com cavalos de polo, porém justificam sua elevação pela condição de estresse causada pelo exercício.
As concentrações séricas de imunoglobulina $G$ ( $\mathrm{IgG}$ ) não se alteraram após a competição e não apresentaram diferença quando comparados os dois grupos de animais avaliados. A IgG tem importante papel no sistema imunológico do animal e seu aumento está descrito durante exercícios de alta intensidade em seres humanos bem-condicionados (Mackinnon et al., 1987).

A imunoglobulina A (IgA) apresentou diminuição de $41,7 \%$ de seu valor inicial após a competição. Os estudos relacionando $\operatorname{IgA} \mathrm{e}$ exercício demonstram um comportamento diferente em relação às outras imunoglobulinas. É vista diminuição de até $50 \%$ dos valores basais em atletas de elite após esforço intenso. Essa queda está relacionada principalmente à imunossupressão causada pelo cortisol e reflete o achado de maior incidência de infecções de vias aéreas superiores em atletas submetidos a grandes esforços (Mackinnon et al., 1987).

As concentrações séricas de albumina e transferrina não apresentaram alteração em seus valores após a competição e quando comparados os dois grupos. A transferrina é classificada, assim como a albumina, como proteína de fase aguda negativa, cujos teores séricos tendem a decrescer na presença de condição inflamatória (Kaneco et al., 1997; Thomas, 2006). Em equinos sua relevância na avaliação do processo inflamatório ainda não foi determinada, porém em bovinos já foi demonstrada diminuição na concentração sérica durante processos inflamatórios crônicos (Thomas, 2006).

Foi constatado o aumento de $21,3 \%$ de uma proteína de peso molecular de $23 \mathrm{kDa}$ ainda não identificada. Gondin et al. (2013) também observaram sua elevação após um jogo-treino de cavalos de polo e sugerem que mais estudos sejam direcionados para o esclarecimento do papel fisiológico dessa proteína no organismo de equinos atletas.

Observou-se também aumento da proteína plasmática total após a competição. Essa elevação pode ser consequência da redistribuição de fluidos do compartimento vascular para o espaço extracelular dos tecidos, ocasionado principalmente pela perda de líquidos através da sudorese dos animais durante o exercício (Kingston, 2008). Acredita-se que essa redistribuição não influencie de forma relevante 
nas concentrações séricas das demais proteínas avaliadas, visto que as alterações observadas apresentaram caráter heterogêneo.

Por definição, a reação de fase aguda é caracterizada pela alteração maior que $25 \%$ nas concentrações de proteínas de fase aguda (Eckersall et al., 2010); portanto, este estudo forneceu evidências que apoiam a hipótese de que a resposta de fase aguda durante o exercício prolongado intenso é equivalente àquela observada quando o organismo sofre desafios inflamatórios e infecciosos. E ainda, as concentrações séricas de haptoglobina podem ser utilizadas como um sinalizador de baixo desempenho nos animais submetidos a esse tipo de exercício.

\section{CONCLUSÃO}

O exercício de longa duração provocou reação de fase aguda, caracterizada por elevação superior a $25 \%$ nas concentrações séricas de haptoglobina, ceruloplasmina e glicoproteína ácida e diminuição nas concentrações séricas de $\operatorname{IgA}$. As concentrações séricas de haptoglobina foram superiores nos animais com baixo desempenho, podendo essas concentrações serem utilizadas como uma ferramenta de avaliação em competições de longa duração.

\section{AGRADECIMENTOS}

Agradecemos o apoio técnico e financeiro da Associação Brasileira de Criadores de Cavalos Crioulos (ABCCC) e a colaboração dos ginetes e proprietários dos animais avaliados neste estudo.

\section{REFERÊNCIAS}

AMARAL, L.A.; MARCHIORI, M.; MARTINS, C.F. et al. Metabolic evaluation of Crioulo horses participating in competitions of $750 \mathrm{~km}$. Pesq.Vet. Bras., v.33, p.1471-1477, 2013.

CECILIANE, F.; GIORDANO, A.; SPAGNOLO, V. The systemic reaction during inflammation: the acute-phase proteins. Protein Pept. Lett., v.9, p.11-23, 2002.

CERÓN, L.L.; ECKERSALL, P.D.; MARTÍNEZ-SUBIELA, S. Acute phase proteins in dogs and cats: current knowledge and future perspectives. Vet. Clin. Pathol., v.34, p.85-99, 2005.
CYWINSKA, A.; GORECKA, R.; SZARSKA, E. et al. Serum amyloid A level as a potential indicator of the status of endurance horses. Equine Vet. J., v.42, p.7-23, 2010.

ECKERSALL, P.D. Acute phase proteins: biomarkers of infection and inflammation in veterinary medicine. Vet. J., v.185, p.7-23, 2010.

FAGLIARI, J.J.; McCLENAHAN, D., EVANSON, O.A. et al. Changes in plasma proteína concentrations in ponies with experimentally induced alimentary laminitis. Am. J. Vet. Res., v.59, p.1234-1237, 1997.

FALLON, K.E. The acute phase response and exercise: the ultramarathon as prototype exercise. Clin. J. Sport Med., v.11, p.38-43, 2001.

FOURNIER, T.; MEDJOUBI, N.N.; PORQUET, D. Alpha-1-acid glycoprotein. Biochim. Biophys. Acta, v.482, p.71-157, 2000.

GONDIN, M.R.; FOZ, N.S.B.; PEREIRA, M.C. et al. Acute Phase Responses of Different Positions of High-Goal (Elite) Polo Ponies. J. Eq.Vet. Scin., v.33, p.956-961, 2013.

GRUYS, E.; OBWOLO, M.J.; TOUSSAINT, M.J.M. Diagnostic significance of the major acute phase proteins in veterinary chemistry: a review. Vet. Bull., v.64, p.1009-1018, 1994.

HIRVONEN, J. Acute phase response in dairy cattle. 2000. 79f. Thesis-Faculty of Medidcine Veterinary University of Helsinki, Helsinki, 2000.

HULTEN, C.; GRONLUND, U.; HIRVONEN, J. et al. Dynamics in serum of the inflammatory markers serum amyloid A (SAA), haptoglobin, fibrinogen and alpha2-globulins during induced noninfectious arthritis in the horse. Equine Vet. J., v.34, p.699-704, 2002.

JACOBSEN, S. Review of equine acute-phase proteins. In: ANNUAL CONVENTION OF THE AMERICAN ASSOCIATION OF EQUINE PRACTITIONERS, 53., 2007, Orlando, Flórida. Proceedings... Orlando: University of Florida. v.53, p.230-235, 2007.

KANEKO, J.J.; HARVEY, J.W.; BRUSS, M.L. (Ed) Clinical biochemistry of domestic animals. San Diego: Academic Press, 932p, 1997.

KENT, J. Acute phase proteins: their use in veterinary diagnosis. Br. Vet. J., v.148, p.279$282,1992$. 
KINGSTON, J.D. Hematologic and serum biochemical responses to exercise and training. In: HINCHCLIFF, GEOR, KANEPS (eds.). Equine Exercise Physiology - The science of exercise in the athletic horse. 1.ed. London: Saunders, 2008. p.397-409.

LAEMMLI, U.K. Cleavage of structural proteins during the assembly of the head of bacteriophage T4. Nature, v.227, p.680-685, 1970 .

MACKINNON, L.T.; CHICK, T.W.; VAN AS, A. et al. The effect of exercise on secretory and natural immunity. Adv. Exp. Med. Biol., v.216, p.62-76, 1987.
MASINI, P.A.; TEDESCHI, D.; BARAGLI, C. et al. Exercise-induced intravascular haemolysis in standardbred horses. Comp. Clin. Path., v.12 p.45-48, 2003.

MURATA, H.; SHIMADA, N.; YOSHIOKA, $M$. Current research on acute phase proteins in veterinary diagnosis: an overview. The Vet. J., v.168, p.28-40, 2004.

THOMAS, J.S. Overview of plasma proteins. In: FELDMAN, B.F.; ZINKL, J.G.; JAIN, N.C. (Ed) Schalm's veterinary hematology. Ames: Blackwell Publising, 2006. p.1344. 